\title{
Estrategia basada en la evaluación auténtica para el desarrollo de competencias digitales en la formación inicial docente
}

\author{
Strategy Based on Authentic Evaluation for the Development of Digital \\ Competences in Teacher Training
}

\section{Estratégia baseada na avaliação autêntica para o desenvolvimento de competências digitais na formação inicial de professores}

\author{
Araceli Camacho-Navarro \\ Universidad Autónoma de San Luis Potosí, Facultad de Psicología, México \\ araceli.camacho@uaslp.mx \\ https://orcid.org/0000-0002-2184-8989 \\ Rolando Javier Salinas-García \\ Universidad Autónoma de Querétaro, Facultad de Psicología, México \\ javier.salinas.uaq@gmail.com \\ https://orcid.org/0000-0003-0307-258X
}

\section{Resumen}

El desarrollo de las competencias digitales en la formación inicial docente es importante para las instituciones que están preocupadas porque sus egresados estén actualizados y capacitados para cumplir con las exigencias de la sociedad actual. El presente trabajo se centró en la planeación e implementación de tres materias optativas para estudiantes de la licenciatura en Psicopedagogía de la Universidad Autónoma de San Luis Potosí (UASLP). La propuesta curricular se basó en la metodología de la investigación evaluativa. El objetivo fue desarrollar las asignaturas con base en el enfoque de la evaluación auténtica de los aprendizajes: desde la selección del contenido hasta la evaluación de las competencias a desarrollar en cada materia. Los resultados demostraron que al cursar las tres materias se 


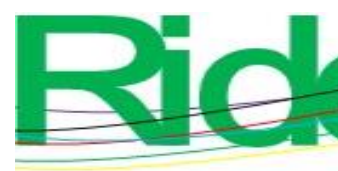

Revista Iberoamericana para la
Investigación y el Desarrollo Educativo
ISSN $2007-7467$

desarrollaron las siguientes competencias en los estudiantes: información y alfabetización informacional, comunicación y colaboración, creación de contenido digital, seguridad y resolución de problemas. Además, la autopercepción de las competencias digitales fue de un nivel intermedio a avanzado, y los estudiantes reconocieron el vínculo entre lo que aprenden en su proceso formativo y lo que realizarán en su práctica profesional.

Palabras clave: competencias del docente, formación del docente, evaluación de la educación, tecnología educativa, TIC.

\begin{abstract}
The development of digital skills in initial teacher training is important for institutions that are concerned that their graduates are updated and trained to meet the demands of today's society. The present work focused on the planning and implementation of three elective subjects for students of the Bachelor of Psychopedagogy at the Universidad Autónoma de San Luis Potosí (UASLP). The curricular proposal was based on the methodology of evaluative research. The objective was to develop the subjects based on the approach of authentic evaluation of learning: from the selection of content to the evaluation of the competencies to be developed in each subject. The results showed that when taking the three subjects, the following competencies were developed in the students: information and information literacy, communication and collaboration, creation of digital content, security and problem solving. In addition, the self-perception of digital skills ranged from an intermediate to advanced level, and the students recognized the link between what they learn in their training process and what they will do in their professional practice.
\end{abstract}

Keywords: teacher qualifications, teacher education, educational evaluation, ICT, educational technology. 


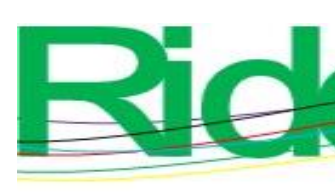

Revista Iberoamericana para la Investigación y el Desarrollo Educativo ISSN $2007-7467$

\section{Resumo}

O desenvolvimento de competências digitais na formação inicial de professores é importante para instituições que se preocupam em que seus egressos sejam atualizados e capacitados para atender as demandas da sociedade atual. O presente trabalho se concentrou no planejamento e implementação de três disciplinas optativas para alunos da licenciatura em Psicopedagogia da Universidade Autônoma de San Luis Potosí (UASLP). A proposta curricular baseou-se na metodologia da pesquisa avaliativa. $\mathrm{O}$ objetivo foi desenvolver as disciplinas com base na abordagem da avaliação autêntica da aprendizagem: desde a seleção do conteúdo até a avaliação das competências a serem desenvolvidas em cada disciplina. Os resultados mostraram que as seguintes habilidades foram desenvolvidas nos alunos ao estudar as três disciplinas: competência informacional e informacional, comunicação e colaboração, criação de conteúdo digital, segurança e resolução de problemas. Além disso, a autopercepção das competências digitais foi de nível intermediário a avançado, e os alunos reconheceram a ligação entre o que aprendem em seu processo de formação e o que farão em sua prática profissional.

Palavras-chave: competências docentes, formação docente, avaliação educacional, tecnologia educacional, TIC.

Fecha Recepción: Junio 2021

Fecha Aceptación: Enero 2022

\section{Introducción}

En el momento en que un docente ingresa a un aula para ejercer su práctica profesional por primera vez hará uso de los conocimientos adquiridos en su formación inicial docente (FID), lo que le permitirá desenvolverse con seguridad en la búsqueda de los objetivos pedagógicos al interactuar con sus estudiantes. Estos conocimientos serán sus herramientas, turbinas que impulsarán el proceso de enseñanza-aprendizaje. Ahí, justamente, radica la importancia de todo a lo que se expuso en su formación docente: de las competencias que desarrolló y las que la institución fue capaz de transmitir en esta etapa formativa.

Las competencias digitales son una caja de herramientas para los docentes en formación que los acompañan tanto para la realización de sus actividades académicas, prácticas profesionales y servicio social como en la elaboración de su tesis para obtener su grado académico. 


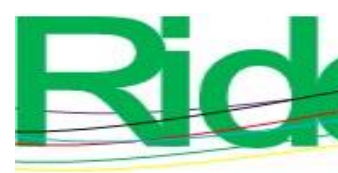

Revista Iberoamericana para la
Investigación y el Desarrollo Educativo
ISSN $2007-7467$

El desarrollo de las competencias digitales es un reto. En los últimos años se ha buscado la mejor manera de implementar una estrategia en donde se involucre a los estudiantes sin caer en cursos meramente técnicos. Y en esa línea, durante la FID, el uso pedagógico de la tecnología digital será uno de los pilares para el cambio hacia una visión más amplia de la tecnología educativa.

Para lograr lo antes descrito, se necesita una congruencia entre el contenido temático, las actividades seleccionadas para ese contenido y los métodos de evaluación. Por tal motivo, se selecciona la evaluación auténtica, pues se erige como una alternativa coherente con lo que se propone y lo que se evalúa, más cuando se trata de competencias.

\section{Competencias digitales docentes}

El docente requiere usar de forma reflexiva las tecnologías de la información y comunicación (TIC). En esa línea, desde una dimensión pedagógica, el desarrollo de las competencias digitales es fundamental. Las TIC son una herramienta muy poderosa, no solo para la representación y transmisión de la información; quizá el aporte más valioso llega cuando el docente las integra al sistema simbólico, y este puede estar presente en cualquier escenario educativo, siempre y cuando existan las condiciones relacionadas con los objetivos educativos que se planearon. Pero para que esto suceda debe existir una apropiación de estas herramientas digitales por parte de los docentes (Valencia et al., 2016).

Las competencias digitales docentes (CDD) en el docente son una necesidad. De hecho, desde hace más de una década ya se declaraba determinante el dominio de dichas competencias. Desde ese entonces, los profesores se enfrentaban a estudiantes de una generación que representaba un cambio cultural en la interacción y el paradigma comunicacional basado en la interactividad (Ministerio de Educación de Chile, 2009).

Actualmente, existe un incremento exponencial de la comunicación a través de las redes sociales por parte de las nuevas generaciones. Además, la aceleración en difusión, acceso y consumo de información y la aparición constante de elementos como realidad aumentada, realidad virtual, memes, etcétera, han transformado la cultura, y como consecuencia, han provocado el cuestionamiento de los modelos y formas tradicionales de enseñanza (Area, 2018). 


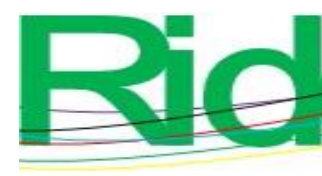

Revista Iberoamericana para la
Investigación y el Desarrollo Educativo
ISSN $2007-7467$

\section{Formación inicial docente}

La detección de las necesidades en la FID requiere de un proceso minucioso, a partir del cual se pueda obtener la suficiente información para tener un alto grado de certeza respecto a los retos a los que se enfrentará el docente en aula. Actualmente, no existen elementos valiosos para la toma de decisiones a futuro y en cuanto a la orientación de este tipo de programas. Al respecto, Gil (2018) destaca que "la evaluación es urgente en los sistemas de formación inicial del docente, porque esta contribuiría a orientar una reforma pendiente, la que nos permitirá formar al profesorado en coherencia con los propósitos del conjunto de la reforma educativa" (p. 260).

En la FID hay un factor que se ha configurado como fundamental a la hora de transformar la práctica educativa: la utilización de las TIC como herramienta en los procesos de enseñanza-aprendizaje. Desde hace varios años esto se ha convertido en una realidad $\mathrm{y}$, a su vez, en una necesidad de utilización para los docentes en profesión.

Lo anterior trae consecuencias no favorables al implementar estrategias en donde se incorporen las TIC en los procesos de enseñanza-aprendizaje. Uno de los principales problemas encontrados por Sancho, Ornellas, Sánchez, Alonso y Bosco (2008) apunta a los sistemas de formación del profesorado que impiden el cambio educativo. Del mismo modo, Pozos y Tejada (2018) consideran relevante la necesidad de formar al docente con un perfil digital: dar un sentido que traspase cursos de divulgación o alfabetización tecnológica y que su avance se dirija más hacia el uso de las TIC en lo pedagógico.

La FID debería ser una oportunidad para los futuros profesionales de potenciar el desarrollo de competencias, habilidades como la autonomía y el compromiso hacia con la práctica educativa; en suma, de desarrollar capacidades y estrategias para afrontar los constantes cambios tecnológicos y sociales que se ven reflejados dentro del aula escolar.

\section{Evaluación auténtica}

La evaluación de competencias es de los procesos más complejos. Para atenuar dicha complejidad aquí se propone la evaluación auténtica. Esta práctica pedagógica trata de construir significados por medio del contenido y los métodos de evaluación de los aprendizajes. 

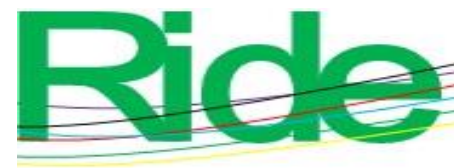

Revista Iberoamericana para la Investigación y el Desarrollo Educativo

ISSN 2007 - 7467

La evaluación auténtica es una alternativa para cambiar la forma de evaluar que actualmente impera, dar un giro al uso de instrumentos estáticos que solo exploran el conocimiento declarativo de tipo factual, como lo señala Díaz (2006). Efectivamente, aquí se busca privilegiar el trabajo autónomo del alumno incorporando metodologías activas que empaten con el modelo basado en competencias (Vallejo y Molina, 2004).

De acuerdo con Díaz (2006):

La aproximación constructivista plantea que no debe haber una ruptura ni un desfase entre los episodios de enseñanza y los de evaluación. Una de las principales críticas posibles a la evaluación que por lo común se realizan en las instituciones educativas es que no hay congruencia entre evaluación y enseñanza, es decir, se enseña una cosa y se evalúa otra (p. 91).

Para una mejor representación de lo que se mencionó en los párrafos anteriores, en la tabla 1 se enlistan las características y condiciones de la evaluación auténtica. 


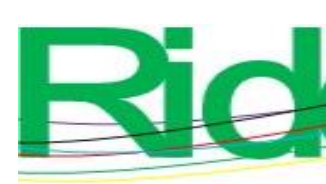

Tabla 1. Diferenciación de la evaluación auténtica

\begin{tabular}{|c|c|}
\hline Enfoque & Características y condiciones \\
\hline $\begin{array}{c}\text { Evaluación } \\
\text { auténtica }\end{array}$ & $\begin{array}{l}\text { - Demanda que los aprendices resuelvan activamente tareas complejas y } \\
\text { - Uuténticas. } \\
\text { relevantes para la solución de problemas reales. } \\
\text { - Busca evaluar lo que se hace. } \\
\text { - Identifica el vínculo de coherencia entre lo conceptual y lo } \\
\text { procedimental. } \\
\text { - Hace un diagnóstico más adecuado de lo que el estudiante sabe y debería } \\
\text { - Saber, así como de lo que desea saber. } \\
\text { Sigue el proceso de adquisición y perfeccionamiento de determinados } \\
\text { - Eaberes o formas de actuación. } \\
\text { Entiende cómo ocurre el desempeño de un contexto o situación } \\
\text { - Valorminada. } \\
\text { confronta con circunstancias relativamente familiares. } \\
\text { Permite al alumno manifestar su verdadero potencial induciéndolo a } \\
\text { comportarse con naturalidad ante cualquier situación. }\end{array}$ \\
\hline
\end{tabular}

Fuente: Elaboración propia con base en Díaz (2006)

Asimismo, Díaz (2006) plantea que se deben reemplazar las pruebas formales escritas y buscar una alternativa que permita lograr un cambio en la cultura de la evaluación imperante, la cual se centra en instrumentos estáticos y que solamente exploran el conocimiento declarativo. En este sentido, es pertinente mencionar que actualmente se ve un creciente uso de procedimientos evaluativos que complementan las pruebas orales o escritas. Guzmán y Ortiz (2019) describen a estos procedimientos como una forma de renovación del proceso de evaluación. 


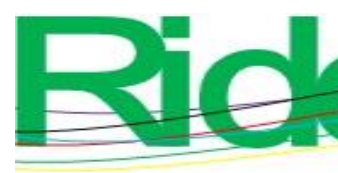

Revista Iberoamericana para la Investigación y el Desarrollo Educativo ISSN 2007 - 7467

La evaluación va a tener sentido cuando represente para los estudiantes una verdadera motivación para el cambio. Como lo menciona Díaz (2006), la "evaluación auténtica se enfoca en el desempeño del aprendiz e incluye una diversidad de estrategias de instrucciónevaluación no solo holistas sino rigurosas" (p. 127).

\section{Objetivo}

El objetivo principal de esta investigación es diseñar una estrategia para el desarrollo de las competencias digitales en los futuros docentes por medio de tres materias optativas basadas en la evaluación auténtica. Del anterior objetivo se desprenden los siguientes objetivos específicos:

- $\quad$ Planear asignaturas en la licenciatura en Psicopedagogía de la Universidad Autónoma de San Luis Potosí (UASLP) que desarrollen las cinco CDD.

- Seleccionar y diseñar el contenido didáctico de las asignaturas con base en el enfoque de la evaluación auténtica.

- $\quad$ Implementar las asignaturas que desarrollen las CDD en los estudiantes de la licenciatura en Psicopedagogía de la UASLP.

\section{Metodología}

En la elección de la metodología, siguiendo a Murueta (2010), se debe evitar lo ecléctico, en donde solamente se elija lo que más agrade de las diferentes alternativas que hay, porque para explicar, justificar y demostrar la validez de cualquier ubicación se tiene que mencionar cómo y por qué se llegó ahí, y no solo eso, también se debe explicar el por qué se sigue ahí.

El término cualitativo generalmente se ha usado en dos sentidos: como cualidad que describe algo y de manera más completa o integral, en donde la cualidad de algún elemento es un conjunto de cualidades o la calidad total de él. La metodología cualitativa no trata del estudio de las cualidades por separado, trata del estudio de un todo integrado que "forma o constituye una unidad de análisis y que hace que algo sea lo que es” (Martínez, 2009, p. 173).

En congruencia con lo anterior, Sandín (2003) considera que "el debate investigación cuantitativa versus cualitativa ha perdido virulencia, y la mayoría de autores se sitúan en una postura integradora y de complementariedad" (p. 18). 


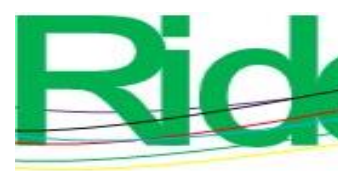

Revista Iberoamericana para la
Investigación y el Desarrollo Educativo
ISSN $2007-7467$

Por su parte, Correa, Puerta y Restrepo (2002) atribuyen el método concreto de la evaluación a la investigación evaluativa, "donde las herramientas de la investigación social se ponen al servicio del ideal consistente en hacer más preciso y objetivo el proceso de juzgar” (p. 31). La investigación evaluativa no pretende contraponerse a una perspectiva cuantitativa en las investigaciones, solamente defiende la idea de que existen diferentes opciones metodológicas y se lleva a cabo con la finalidad de obtener resultados fundamentados para la toma de decisiones posteriores a la investigación, como lo declara Escudero (2016).

Al ser parte de un proceso de investigación, la evaluación establece criterios claros y específicos que garantizan el éxito del proceso; reúne sistemáticamente información, pruebas y testimonios de una muestra representativa de las audiencias que conforman el programa $\mathrm{u}$ objeto para evaluar; traduce dicha información a expresiones valorativas y las compara con los criterios inicialmente establecidos, y finalmente saca conclusiones.

Suchman (1967) hace una diferenciación entre los objetivos y las facultades investigativas de la evaluación, y las contrapone con la investigación básica o pura; se trata de una "compleja mezcla de distintos valores, propósitos y recursos" (p. 71).

En función de lo planteado en los párrafos anteriores, se definió el diseño metodológico basado en la investigación evaluativa. Se trata del que mejor se adapta para este trabajo de investigación por la naturaleza de valoración para la estrategia.

En esta estrategia propuesta se concentró el trabajo en el desarrollo de tres materias optativas para estudiantes de la licenciatura en Psicopedagogía de la UASLP.

- Optativa uno: "Las TIC en la educación”.

- Optativa dos: "Entorno virtuales de enseñanza-aprendizaje (Evea) y plataformas educativas".

- Optativa tres: "Creación de recursos educativos digitales".

Los estudiantes de las tres materias optativas que se proponen en el estudio quedaron distribuidos como se muestra en la tabla 2. Aquí cabe aclarar que las materias optativas solo se ofertan para los estudiantes que se encuentran cursando el sexto semestre en adelante y la carga de materias está sujeta a disponibilidad y donde los primeros en seleccionar son aquellos estudiantes que tienen mejor promedio. 

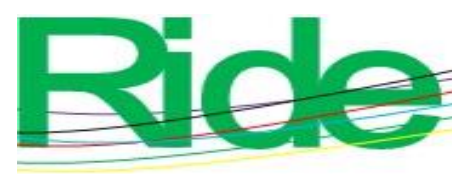

Tabla 2. Distribución de estudiantes por materia optativa

\begin{tabular}{|c|c|}
\hline Materia optativa & Núm. de estudiantes \\
\hline 1) Las TIC en la educación & 12 \\
\hline 2) Evea y plataformas educativas & 29 \\
\hline $\begin{array}{l}\text { 3) Creación de recursos educativos } \\
\text { digitales }\end{array}$ & 27 \\
\hline Total & 68 \\
\hline
\end{tabular}

Fuente: Elaboración propia

Las fases para llevar a cabo la estrategia fueron las siguientes:

1) Planeación de las materias optativas.

2) Selección del contenido y métodos de evaluación.

3) Implementación.

\section{Fase 1. Planeación de las materias optativas}

Se realiza una planeación, desarrollo y evaluación basado en el enfoque de autenticidad, porque, como lo mencionan Jalo y Pérez (2016), el concepto no solo se refiere a la evaluación, sino al aprendizaje que se genera al enseñar y al evaluar.

Al momento hablar de evaluación de competencias se tiene que tomar en cuenta aspectos tales como la adquisición de conocimientos, habilidades y actitudes, aspectos que para la evaluación tradicional es complicado cubrir (Córdoba, 2013)

Las competencias digitales a desarrollar por medio de la propuesta de las materias antes mencionadas se ilustran en la figura 1. 

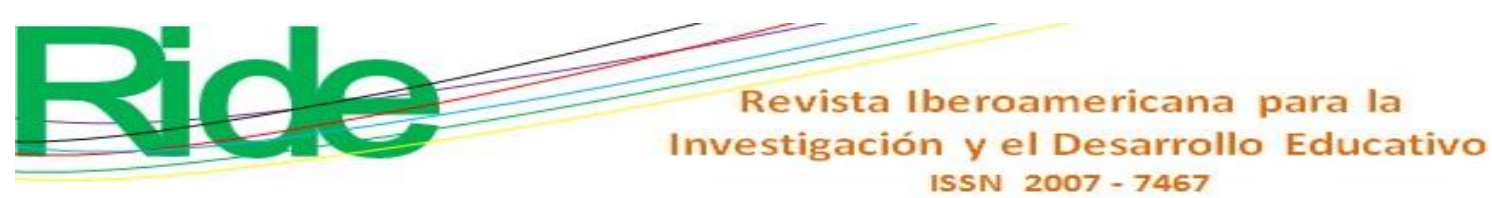

Figura 1. Distribución de las competencias digitales que se desarrollan en la propuesta de las materias optativas

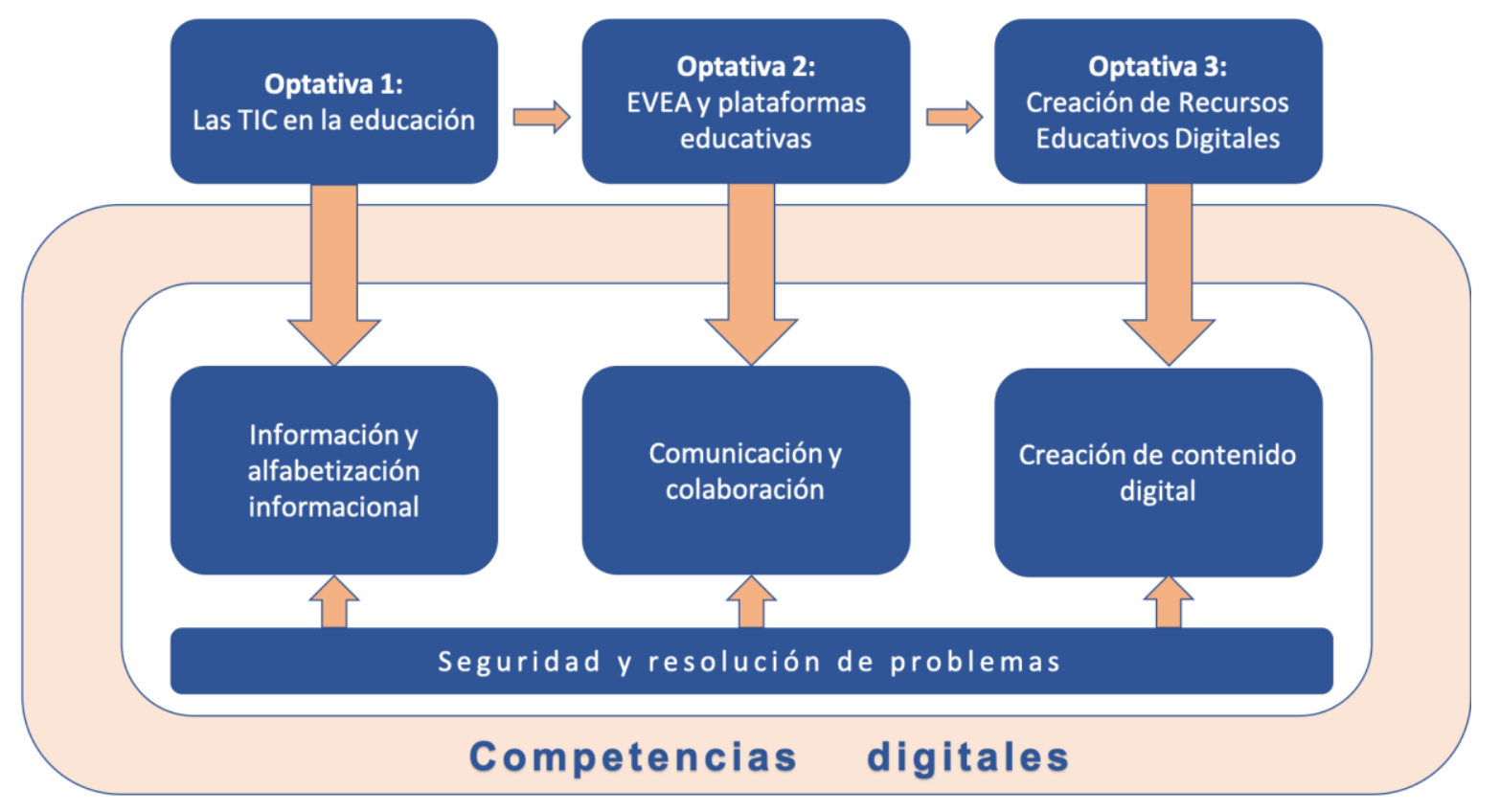

Fuente: Elaboración propia

Es cierto que no hay situaciones didácticas únicas o idóneas preestablecidas al momento de enseñar o evaluar competencias; es necesario recrearlas con la mayor autenticidad posible con casos propios o problemáticas de acuerdo con la práctica de la profesión (Díaz, 2019, p. 55).

\section{Fase 2. Selección del contenido y métodos de evaluación}

La selección del contenido partió de la idea que la educación se ha centrado en los resultados, pero ha dejado un poco de lado los medios por los cuales se logra el aprendizaje, y se le dio prioridad a estos medios para poder desarrollar las competencias planteadas desde un inicio en cada una de las materias propuestas.

De acuerdo con lo anterior, se reconoce una tríada que incluye al docente, los estudiantes y el contenido de las materias, que conformarán una serie de vínculos o entretejidos para la construcción del conocimiento. Asimismo, Litwin (2009) sostiene que se identifican tres formas de uso de la tecnología: "según el lugar que se le asigne al docente, según la concepción del sujeto de aprendizaje que se asuma y según el sentido con el que se entiende el contenido en la enseñanza" (p. 22). 

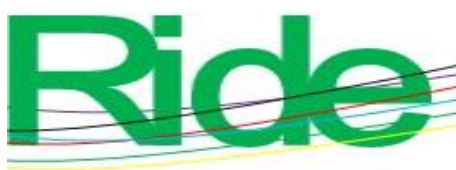

Revista Iberoamericana para la Investigación y el Desarrollo Educativo

ISSN 2007 - 7467

En este apartado se concentra el proceso de identificar, seleccionar y diseñar el contenido de cada una de las materias optativas propuestas. Igualmente, la definición de los métodos de evaluación. Como se mencionaba en párrafos anteriores, las propuestas didácticas deben ser lo más auténticas posible, que las actividades resuelvan problemáticas apegadas a la práctica de la profesión. Para ello, la evaluación auténtica es ideal.

Desde una perspectiva general, se analizan las tareas que los docentes realizan al momento de transmitir los contenidos. Primero seleccionan, luego ordenan y jerarquizan la información, señala Litwin (2009). Este proceso requiere una mirada crítica para identificar si es relevante o adecuada la información que se considera utilizar, tomando en cuenta el contexto, el grado y, en este caso, las competencias que se pretenden desarrollar en los estudiantes.

En sintonía con lo anterior, se seleccionaron los contenidos de cada una de las materias optativas considerando las competencias que se planeaban desarrollar en ellas, y de acuerdo con el Marco común de competencia digital docente que dicta el Instituto Nacional de Tecnologías Educativas y de Formación del Profesorado [Intef] (2017), quedaron distribuidas como como se muestra en la figura 2, la figura 3 y la figura 4.

Figura 2. CDD que se desarrollan en la materia optativa "Las TIC en la educación"

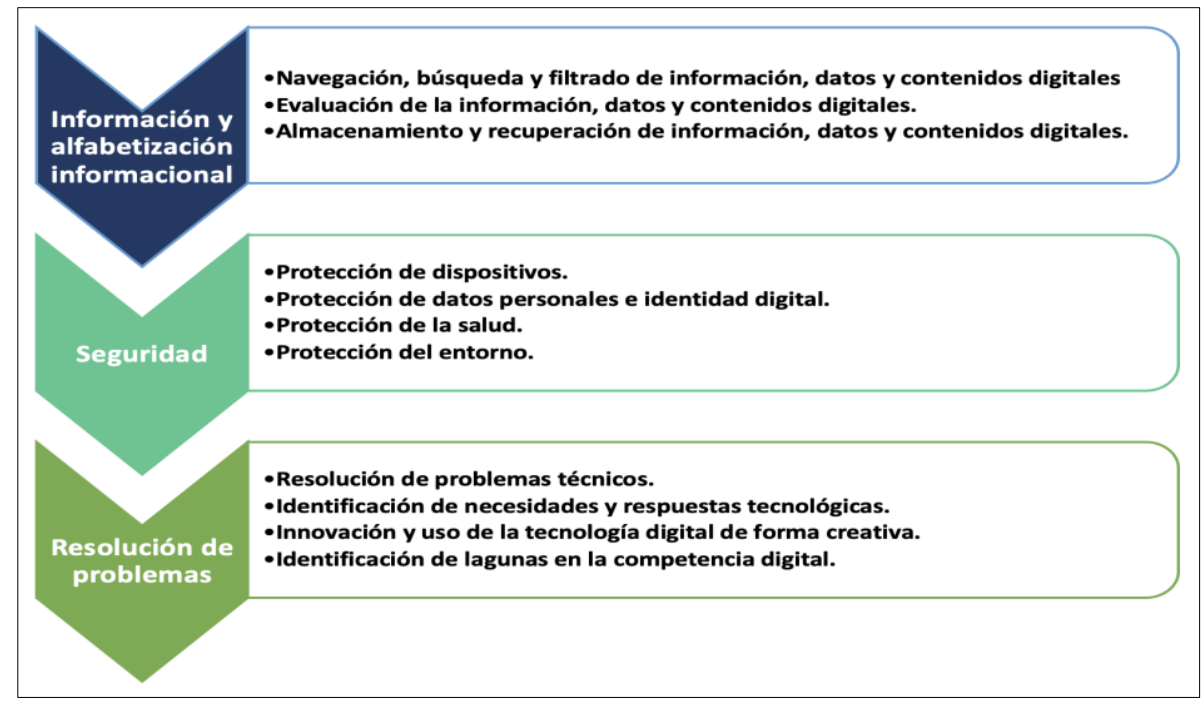

Fuente: Elaboración propia 

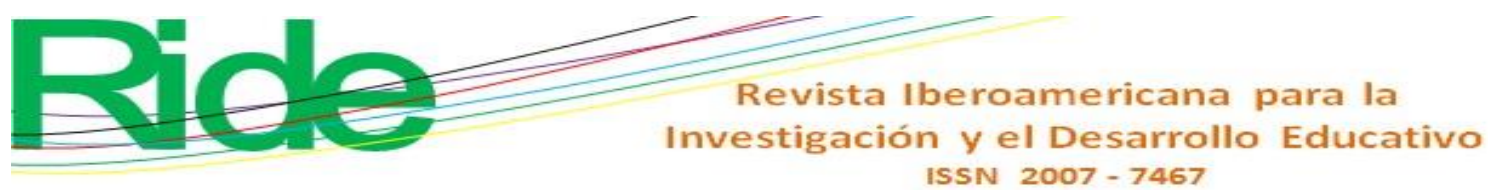

Después de seleccionar el contenido temático en las materias, el enfoque fue que los estudiantes se reconocieran y profundizaran en cosas particulares sobre su práctica profesional como futuros psicopedagogos, en donde se implicara la resolución de problemas que provocara aprendizajes a través de la observación o imitación del uso de las tecnologías digitales en escenarios muy parecidos a su praxis.

Las materias estuvieron divididas en tres parciales, por motivos académicos y administrativos. En cada parcial se trató de implementar un conjunto de actividades, tareas y realización de proyecto para que no se llevara a cabo una simple ponderación numérica, sino una evaluación formativa con diferentes instrumentos y, a su vez, poder evaluar las competencias que se planearon para cada una de las asignaturas, como se puede ver en la figura 5, figura 6 y figura 7.

Figura 5. Secuencia de actividades desarrolladas en la materia optativa "Las TIC en la educación"

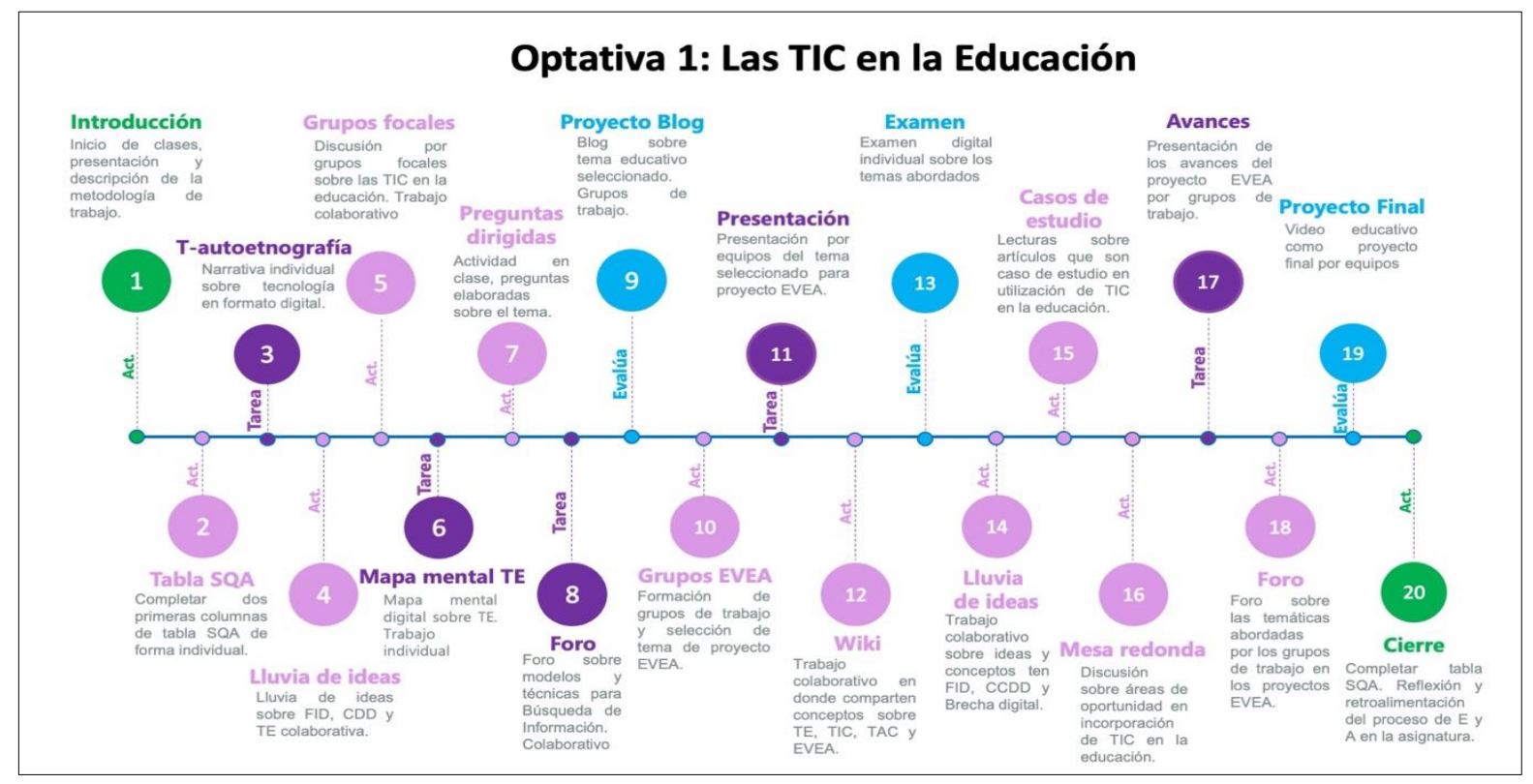

Fuente: Elaboración propia con base en Castañeda (2019) 


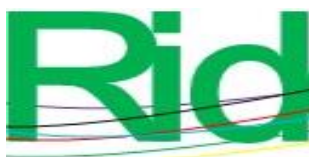

Revista Iberoamericana para la Investigación y el Desarrollo Educativo ISSN 2007 - 7467

Figura 6. Secuencia de actividades desarrolladas en la materia optativa "Evea y plataformas educativas"

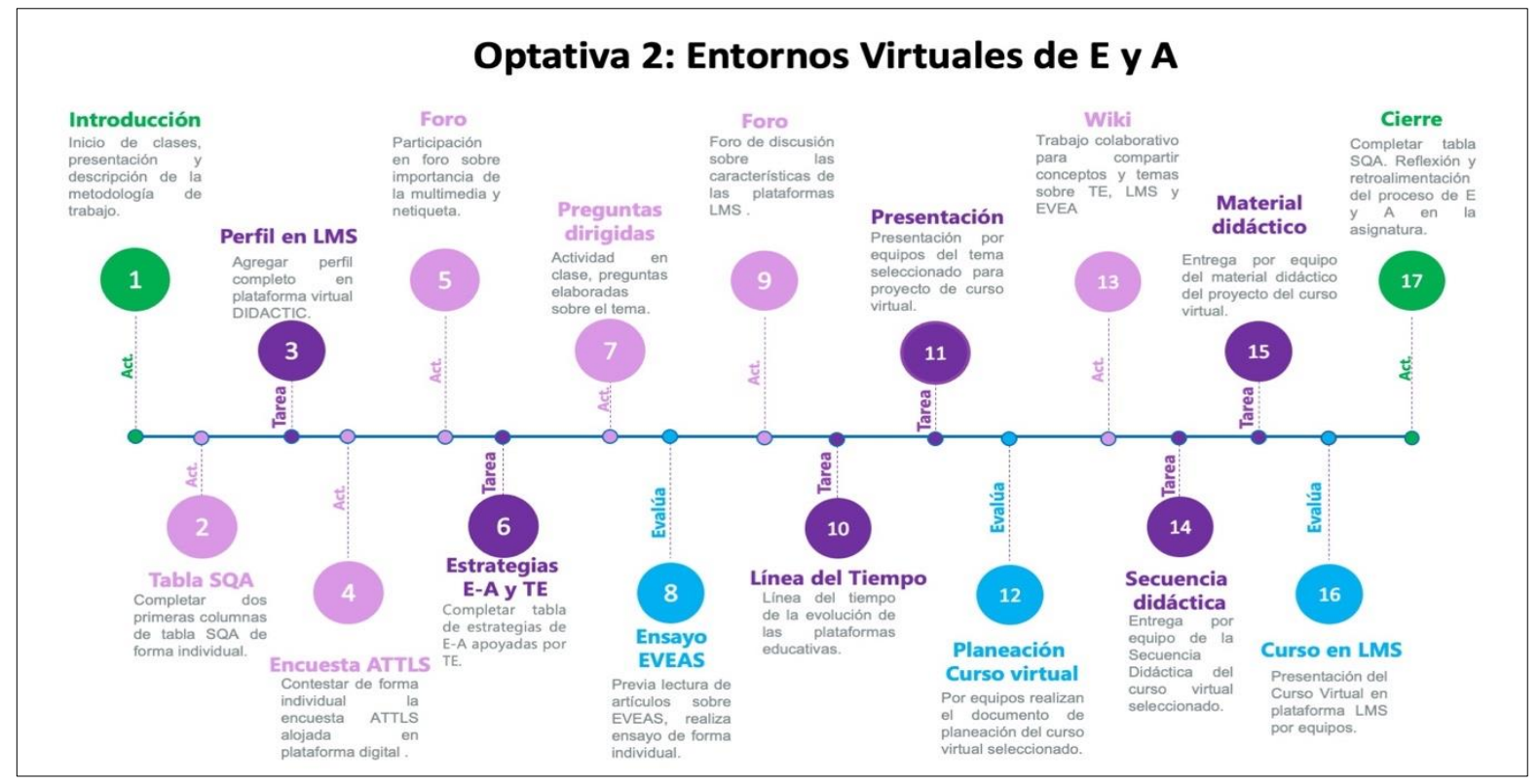

Fuente: Elaboración propia con base en Castañeda (2019)

Figura 7. Secuencia de actividades desarrolladas en la materia optativa "Creación de recursos educativos digitales"

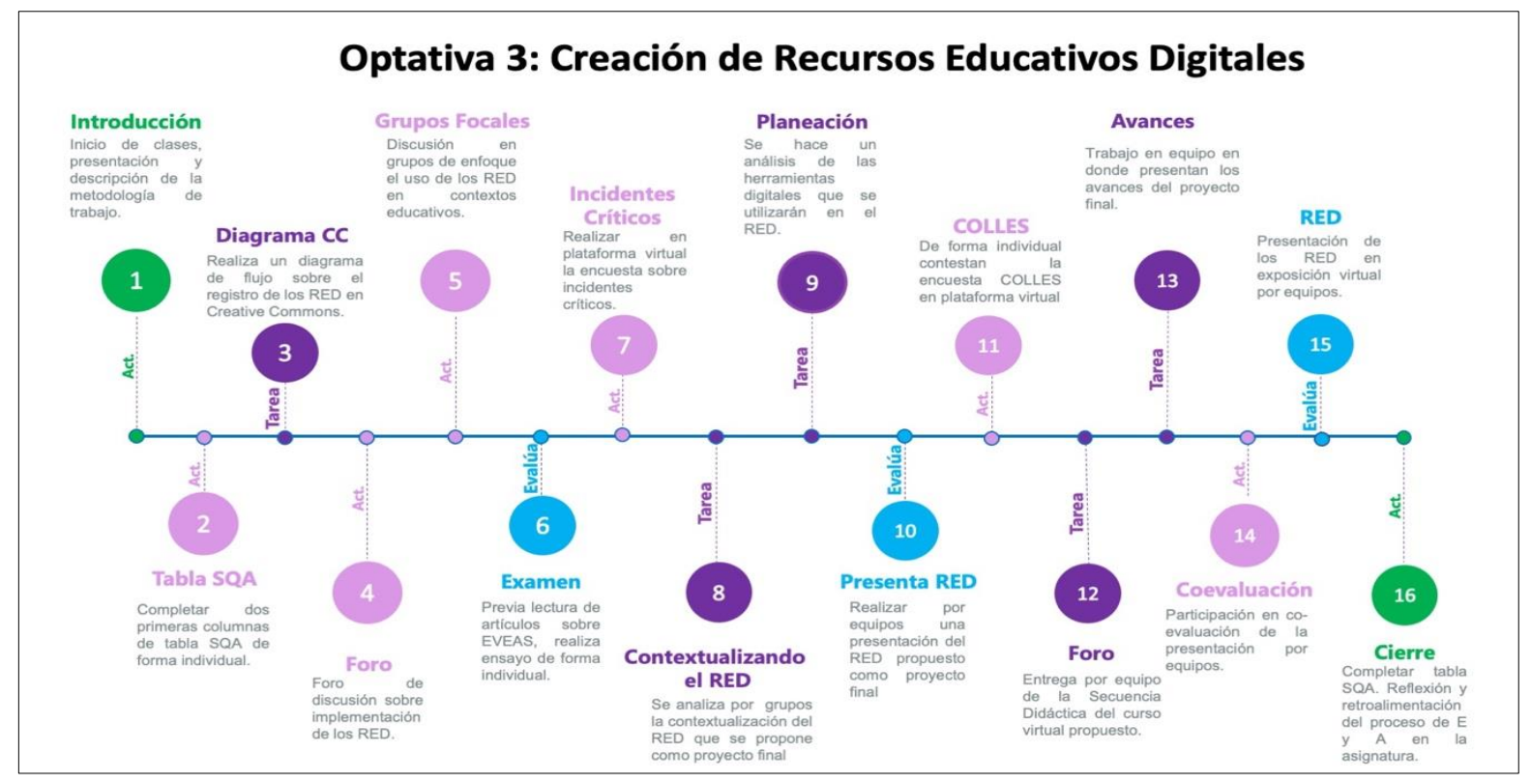

Fuente: Elaboración propia con base en Castañeda (2019) 


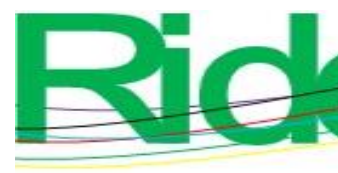

Revista Iberoamericana para la
Investigación y el Desarrollo Educativo
ISSN $2007-7467$

Las tres materias optativas tuvieron diferentes escenarios en los cuales se trabajaron las diferentes competencias digitales. Estos ambientes de enseñanza-aprendizaje estaban determinados por las actividades planeadas, al igual que por la infraestructura tecnológica con la que se contaba en ese momento en la Facultad de Psicología de la UASLP para uso académico, a saber:

- Aula tradicional: aula en el edificio donde se imparten las diferentes materias que corresponden a la licenciatura en Psicopedagogía. Están equipadas con pizarrón, proyector, bocinas y conexión a internet.

- Aula TIC: aula en el edificio administrativo que se utiliza para videoconferencias. Cuenta con computadoras para los estudiantes, conexión a internet, equipo especializado para videoconferencias, pizarrón inteligente y proyector.

- DidacTIC: plataforma virtual institucional basada en Moodle para impartir clases correspondientes a las diferentes licenciaturas en la UASLP. Se solicita el espacio a la Secretaría Académica de la universidad y se activa con los estudiantes inscritos en la materia.

- Microsoft Teams: plataforma virtual gratuita para uso académico y administrativo por integrantes de la comunidad UASLP. Por medio del correo y el usuario institucional se genera un espacio en la plataforma en donde se diseña el curso de las materias.

- Videoconferencias: para mantener la comunicación se mantuvieron sesiones síncronas apoyadas por tres herramientas digitales: Skype, Zoom y Teams. La selección de ellas estuvo determinada por la estabilidad de la conexión y la facilidad para realizar las actividades planeadas.

Los espacios antes descritos fueron utilizados en diferentes momentos en cada una de las asignaturas optativas. A continuación, en la tabla 3, se muestra el uso de la infraestructura y herramientas digitales presentes en las materias optativas. 


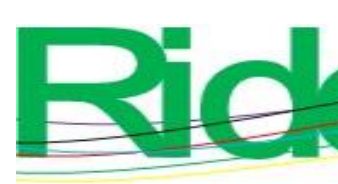

Revista Iberoamericana para la Investigación y el Desarrollo Educativo ISSN 2007 - 7467

Tabla 3. Ambientes y escenarios presentes en las materias optativas

\begin{tabular}{|c|c|c|c|c|c|}
\hline Materia & $\begin{array}{c}\text { Aula } \\
\text { tradicional }\end{array}$ & Aula TIC & Didactic & Teams & VCF* \\
\hline $\begin{array}{c}\text { Las TIC en la } \\
\text { educación }\end{array}$ & $X$ & $X$ & $X$ & - & $X$ \\
\hline $\begin{array}{c}\text { Evea y plataformas } \\
\text { educativas }\end{array}$ & $X$ & $X$ & $X$ & - & $X$ \\
\hline $\begin{array}{l}\text { Creación de recursos } \\
\text { educativos digitales }\end{array}$ & $X$ & - & $X$ & $X$ & \\
\hline \multicolumn{2}{l}{\begin{tabular}{l} 
Nota: *Videoconferencias \\
\hline
\end{tabular}}
\end{tabular}

Fuente: Elaboración propia

\section{Resultados}

El proceso de evaluación en las materias optativas presentó una nueva forma de interactuar en los procesos de enseñanza-aprendizaje, especialmente en los estudiantes como participantes activos y asumiendo el papel de gestor de su propio aprendizaje, algo que en la educación formal se dificulta pero que se puede lograr con la disposición y sentido de responsabilidad de los que intervienen en dicho proceso, es decir, desde el que enseña hasta el que aprende.

Es importante señalar que en cada una de las materias optativas se realizó un proyecto acorde a lo que se planteaba en el contenido temático y respondiendo a las CDD planteadas. Por supuesto, sirvió para evaluar el aprendizaje y la enseñanza: los alumnos demostraron haciendo y no solamente se asumió lo que ellos pensaban saber o lo que decían saber; esto es importante al momento de evaluar competencias en las asignaturas y se puede decir que es una estrategia de las más auténticas al respecto, porque recoge toda la información, las actividades y contenidos en un solo proyecto.

En la optativa uno el proyecto final fue un video sobre un tema educativo que se insertó en un blog realizado por equipos. En la optativa dos, el proyecto abordó una temática educativa en una plataforma LMS seleccionada por equipos, en donde los alumnos trabajaron desde la planeación hasta la secuencia didáctica, selección de los REDA e implementación. Para finalizar, en la optativa tres, los estudiantes, como proyecto final, realizaron un recurso educativo digital, y se realizó una exposición virtual de cada uno de ellos, a la cual se 


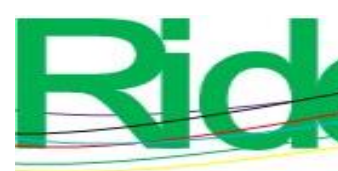

Revista Iberoamericana para la Investigación y el Desarrollo Educativo ISSN 2007 - 7467

invitaron a todos los docentes y estudiantes de la licenciatura en Psicopedagogía y la Facultad de Psicología de la UASLP.

Implementar las asignaturas con este tipo de actividades y evaluaciones en todo el proceso fue interesante y complejo, puesto que se tuvieron que considerar muchos factores externos, por ejemplo, la infraestructura digital en la carrera en cuestión y de forma individual con los estudiantes, el tiempo, la disposición y la carga de trabajo tanto de los estudiantes para realizar las actividades como del docente para evaluarlas.

Las materias estuvieron integradas por diferentes participantes, ya que, al ofertarse como optativas, se crearon grupos heterogéneos. Por la misma razón, fue complejo evaluar las tres optativas como un todo. A raíz de los hechos, se identificó al grupo de estudiantes que llevaron las tres asignaturas, y de un análisis de los tres grupos se obtuvo como resultado que fueron en total 12 estudiantes los que participaron en las tres.

Sobre la base de las ideas expuestas, era importante evaluar la competencia digital desarrollada por los estudiantes que tuvieron la oportunidad de participar en las tres materias optativas y analizar cada una de las áreas referidas en ellas, por tal motivo se aplicó un cuestionario en Google Forms para analizar la autopercepción del desarrollo de las CDD solamente a estos 12 estudiantes mencionados anteriormente.

El cuestionario estuvo dividido en las cinco áreas señaladas por el Intef (2017), con sus respectivas dimensiones. En total, 21 ítems diseñados para identificar el nivel de CDD. El cuestionario se adaptó al contexto de la investigación y por lo mismo se agregó una sección más para conocer la opinión de los estudiantes sobre el desarrollo de las tres materias, con el fin de conocer su nivel de satisfacción sobre la forma de impartir las clases por la docente, la selección del contenido en cada una de ellas e identificar la utilidad de estas en los diferentes escenarios con los que interactuaban en su FID. Además, al final se hizo una pregunta abierta de tipo opinión para obtener retroalimentación de la estrategia en general. De esta forma, se obtuvieron los siguientes resultados:

Información y alfabetización informacional. Tomando en cuenta el desarrollo de las competencias señaladas por el Intef (2017), correspondientes a identificar, localizar, obtener, almacenar, organizar y analizar información digital, datos y contenidos digitales, evaluando su finalidad y relevancia para las tareas docentes, destaca que la mayoría de los 12 participantes se mantiene en un nivel intermedio y avanzado, como se muestra en la figura 8. 

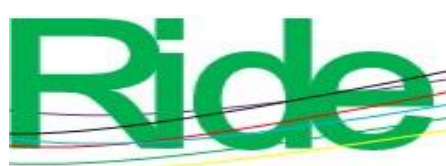

Revista Iberoamericana para la Investigación y el Desarrollo Educativo

ISSN 2007 - 7467

Figura 8. Percepción de la CDD en el área 1) Información y alfabetización informacional

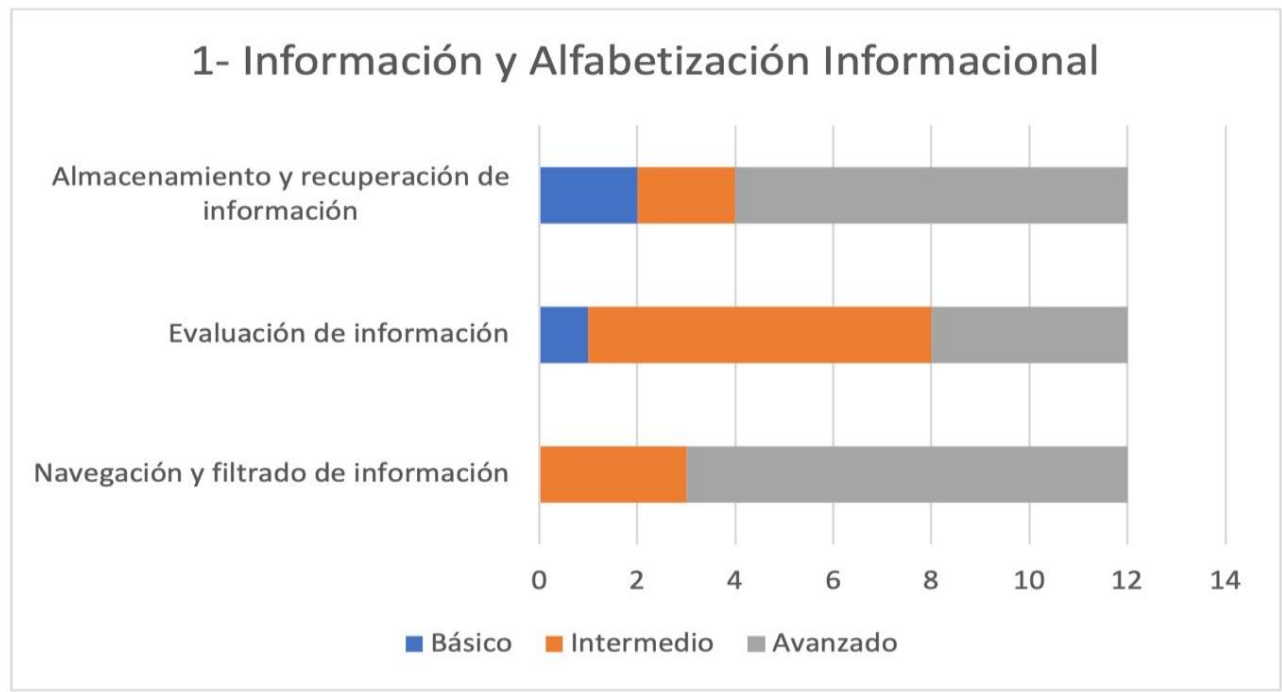

Fuente: Elaboración propia

Comunicación y colaboración. En el caso de los resultados que se relacionan con la comunicación llevada a cabo en entornos digitales especificados por el Intef (2017), y que se relacionan con compartir recursos a través de herramientas en línea, hacer conexión y colaboración con otros a través de herramientas digitales, interactuar y participar en comunidades y redes, se observa, decíamos, que la mayoría de los 12 participantes se mantienen en los niveles intermedio y avanzado, como se puede ver en la figura 9.

Figura 9. Percepción de la CDD en el Área 2- Comunicación y colaboración.

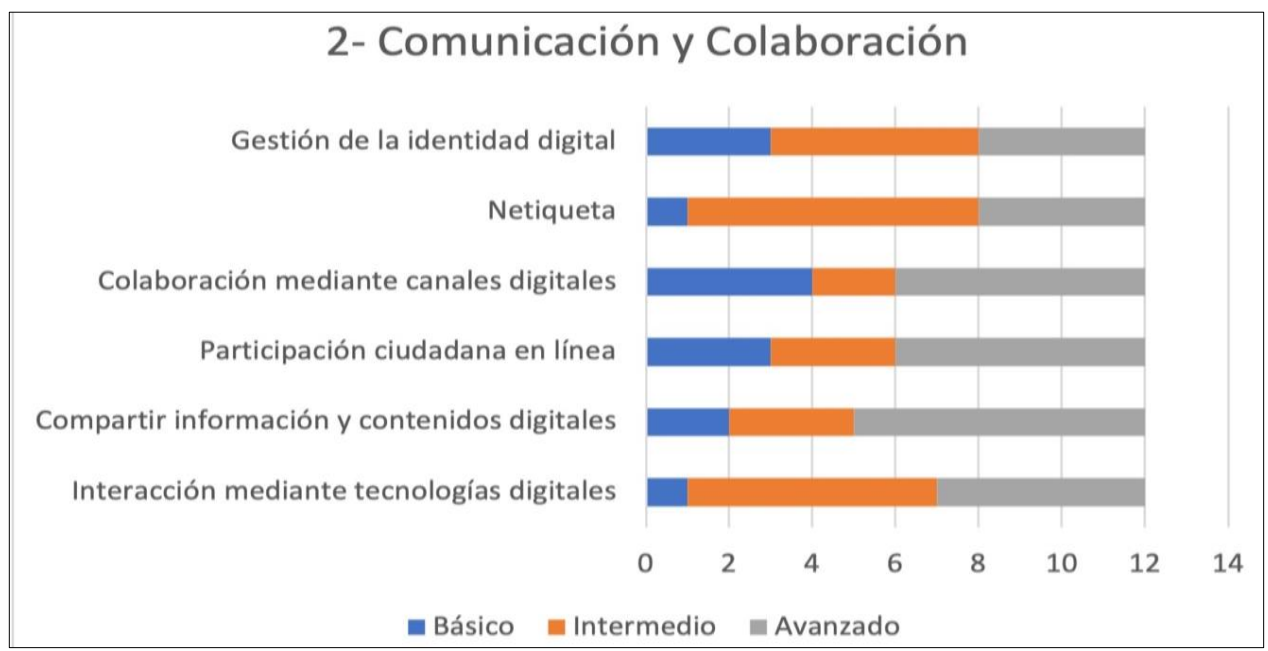

Fuente: Elaboración propia 

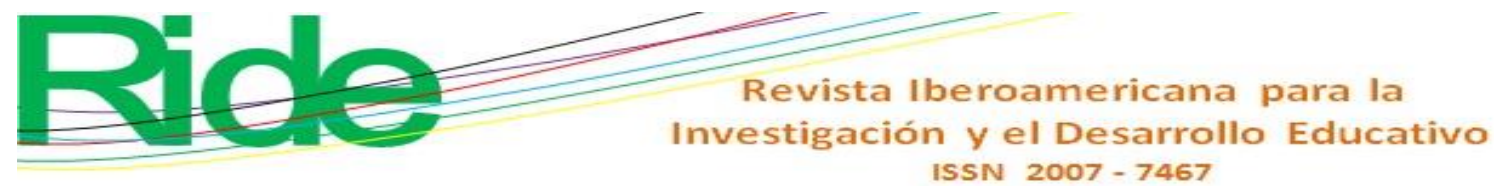

Creación de contenido digital. Al analizar esta área descrita por el Intef (2017), que abarca la creación y edición de contenidos digitales, integración y reelaboración de conocimientos y contenidos previos, realización de producciones artísticas, contenidos multimedia y programación informática, saber aplicar los derechos de propiedad intelectual y las licencias de uso, la información manifiesta que la mayoría de los 12 participantes se desenvuelve en los niveles intermedio y avanzado. Cabe señalar que, en el apartado de programación, seis de los participantes tienen la autopercepción de que solo conocen los conceptos y fundamentos básicos de la informática y la tecnología móvil en la educación, por lo que se posicionaron en un nivel básico. Lo anterior se muestra en la figura 10.

Figura 10. Percepción de la CDD en el área 3) Creación de contenido digital

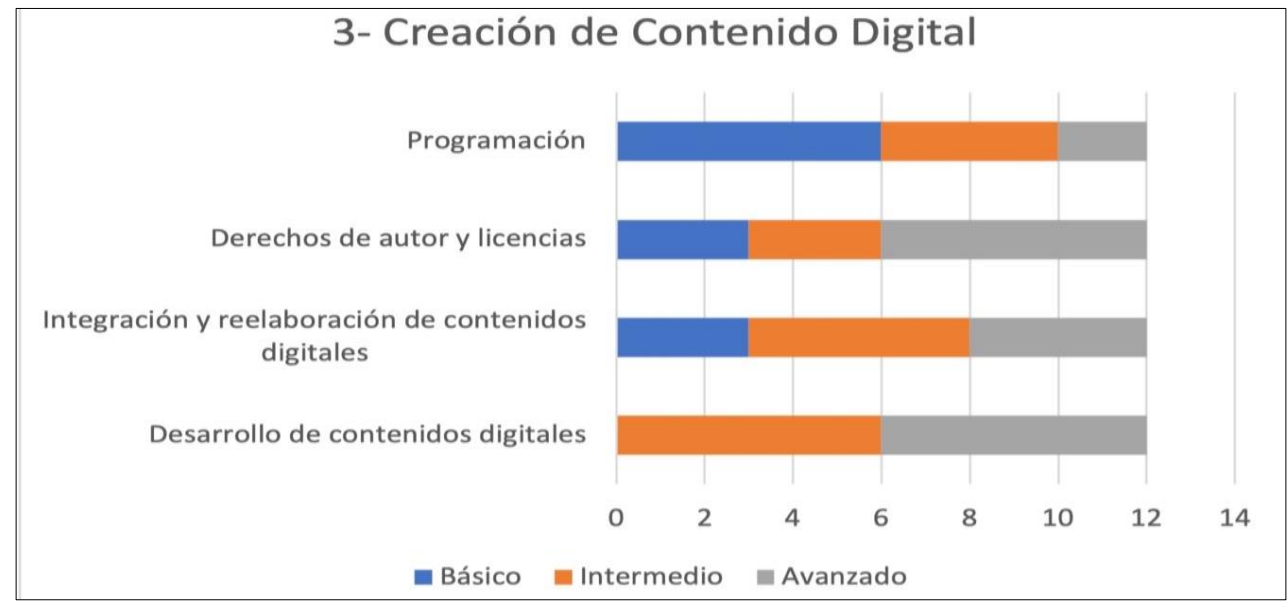

Fuente: Elaboración propia

Seguridad. En este apartado el Intef (2017) se enfoca en la protección de información y datos personales, protección de la identidad digital, protección de los contenidos digitales, medidas de seguridad y uso responsable y seguro de la tecnología. Los participantes, en su mayoría, se posicionan en el nivel intermedio y avanzado en estas competencias digitales. Es de destacar que en el tema de las competencias digitales que comprenden a la protección de la salud todos ellos consideran que saben cómo protegerse a sí mismos y a otros del ciberacoso y entienden los riesgos para la salud asociados al uso de tecnologías (desde los aspectos ergonómicos hasta la adicción a las tecnologías), al posicionarse en el nivel intermedio y avanzado, como se observa en la siguiente figura 11. 


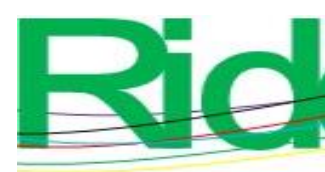

Revista Iberoamericana para la Investigación y el Desarrollo Educativo ISSN 2007 - 7467

Figura 12. Percepción de la CDD en el área 5) Resolución de problemas

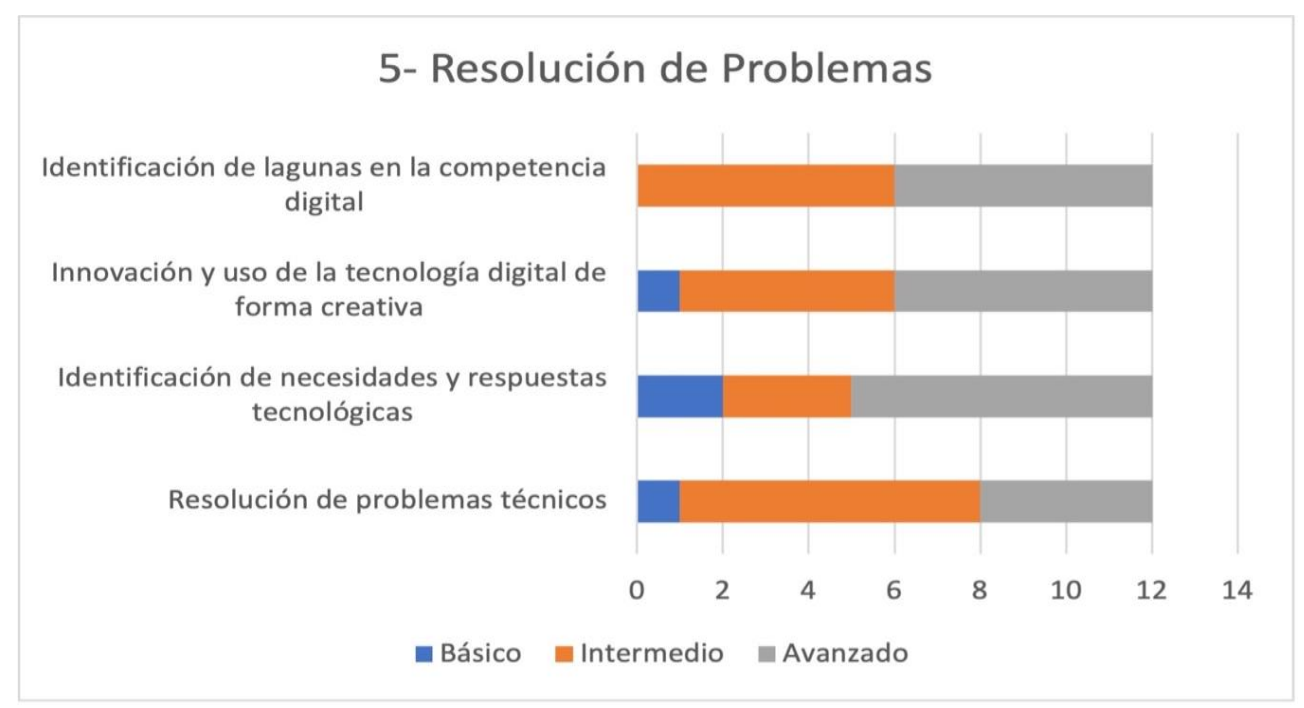

Fuente: Elaboración propia

Llegado a este punto cabe aclarar que de los 12 participantes que conforman este grupo, dos se encontraban con estatus de pasante en la licenciatura en Psicopedagogía y dos más como profesionistas; los ocho restantes todavía se encontraban como estudiantes en la facultad. En el cuestionario aplicado se pide una breve descripción del empleo que desempeñan y las dos egresadas mencionaron que se desarrollan como "Apoyo educativo en clases virtuales".

A continuación, consideramos pertinente exponer los resultados obtenidos sobre la importancia y utilidad de las tres materias optativas que desarrollan competencias digitales en los estudiantes de la licenciatura en Psicopedagogía de la UASLP, y que permiten un mejor desarrollo y participación en los diferentes escenarios de todo su proceso formativo y en su futura práctica profesional. Así pues, es importante destacar que, de acuerdo con los datos obtenidos, hay una identificación por parte de todos los participantes en la utilidad de estas materias como parte de su formación inicial (figura 13). 

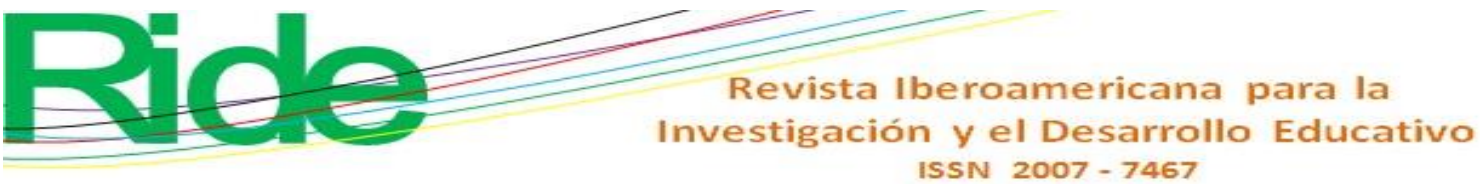

Figura 13. Utilidad percibida de las tres materias optativas en los diferentes escenarios formativos de la licenciatura en Psicopedagogía de la UASLP

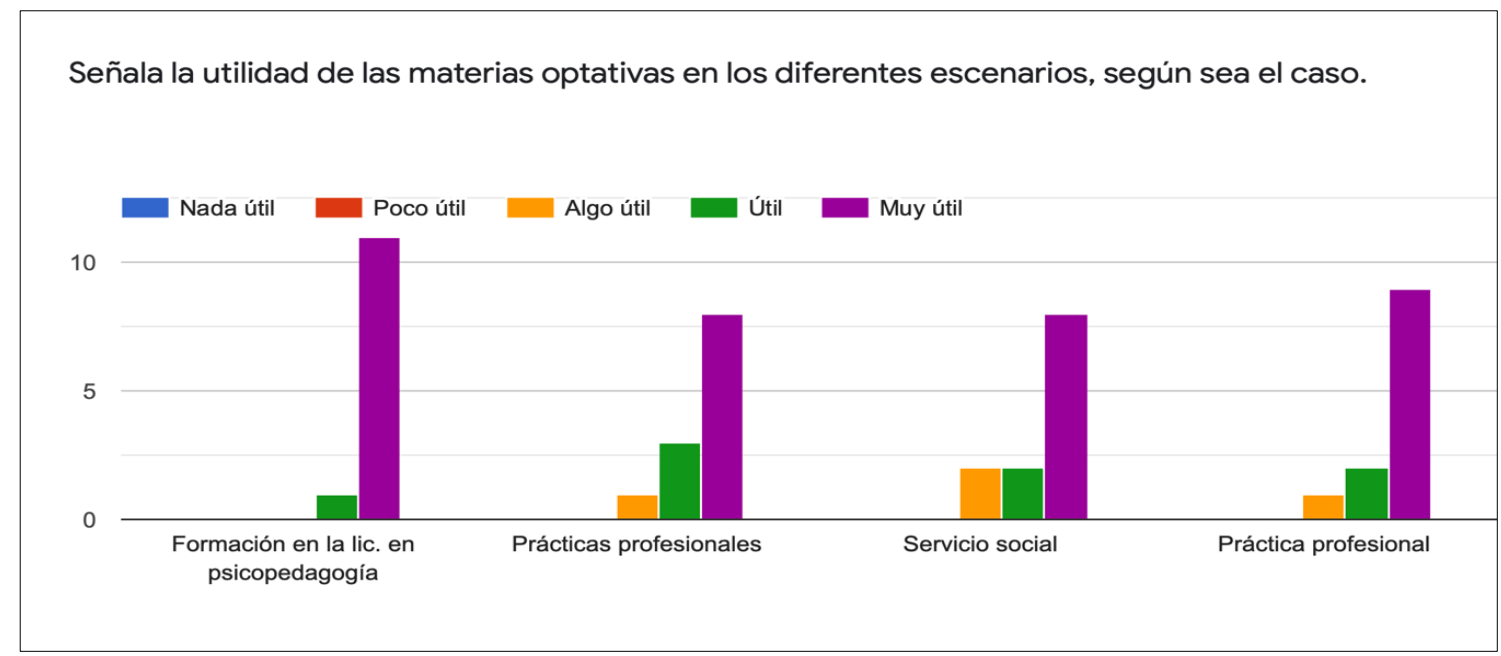

Fuente: Elaboración propia

Por lo que se refiere al desarrollo e implementación de las tres materias optativas, también se buscó obtener una respuesta por parte del grupo de los 12 estudiantes. Se examinó la percepción de la pertinencia de los contenidos, la forma de impartir las clases y la selección de las actividades y métodos de evaluación, todo en escala de Likert, en donde el uno era la peor calificación y el cinco la mejor. En resumen, dado los resultados obtenidos, podemos afirmar que el desarrollo e implementación de la estrategia fue positiva y bastante alentadora.

En la parte de "Pertinencia de los contenidos", dos estudiantes señalaron con un puntaje de 4 y 10 con puntaje de 5. Cabe mencionar que los dos estudiantes expresaron en la encuesta que les hubiera gustado que se abordara más sobre el tema de la gamificación, herramientas digitales con propósito específico para edición de video y programación de juegos. Los resultados se pueden observar en la siguiente figura 14. 


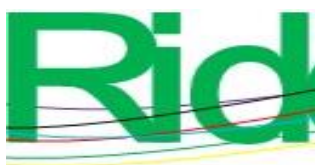

\section{Revista Iberoamericana para la Investigación y el Desarrollo Educativo ISSN 2007 - 7467}

Figura 14. Pertinencia de los contenidos en las tres materias optativas

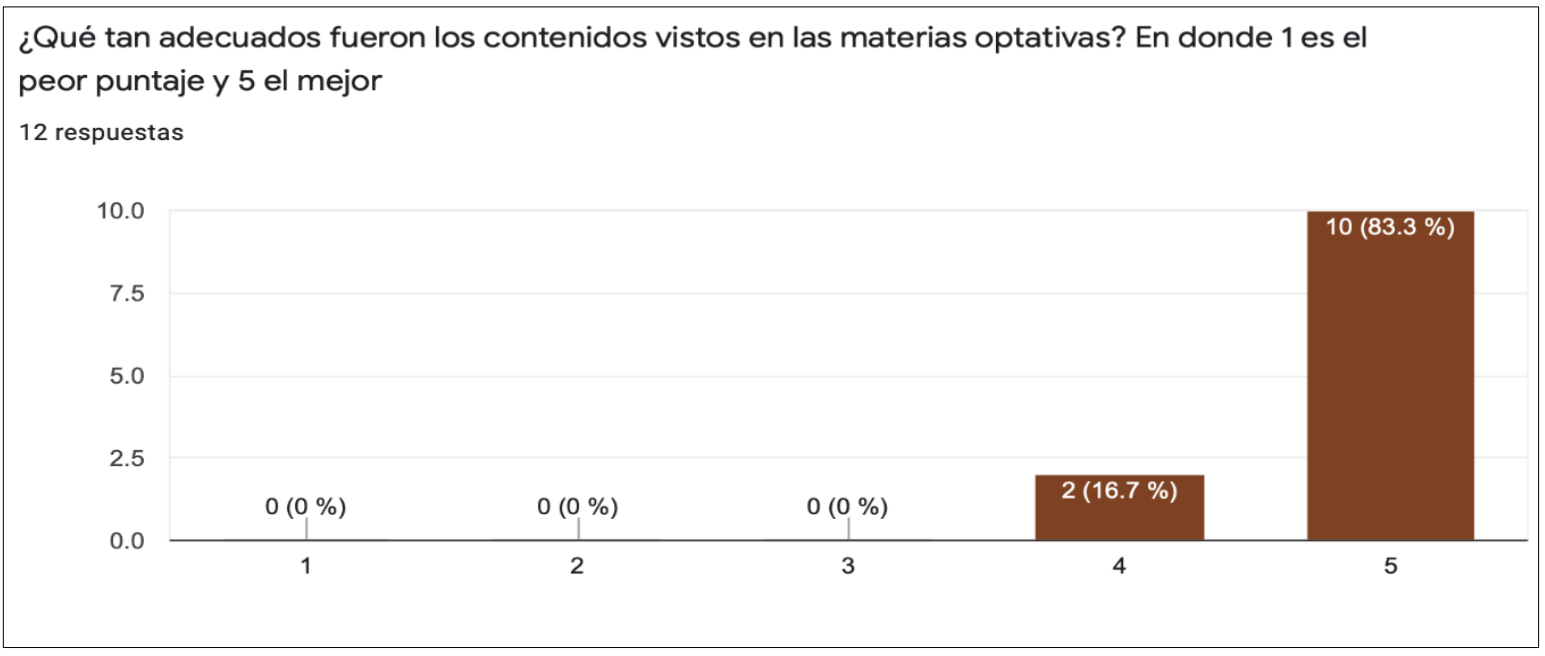

Fuente: Elaboración propia

En la indagación de la forma de impartir las materias, las actividades y métodos de evaluación, se puede concluir que los participantes consideran que fue muy pertinente el desarrollo, como se muestra en las figuras 15 y 16 .

Figura 15. Impartición de las clases en las tres materias optativas

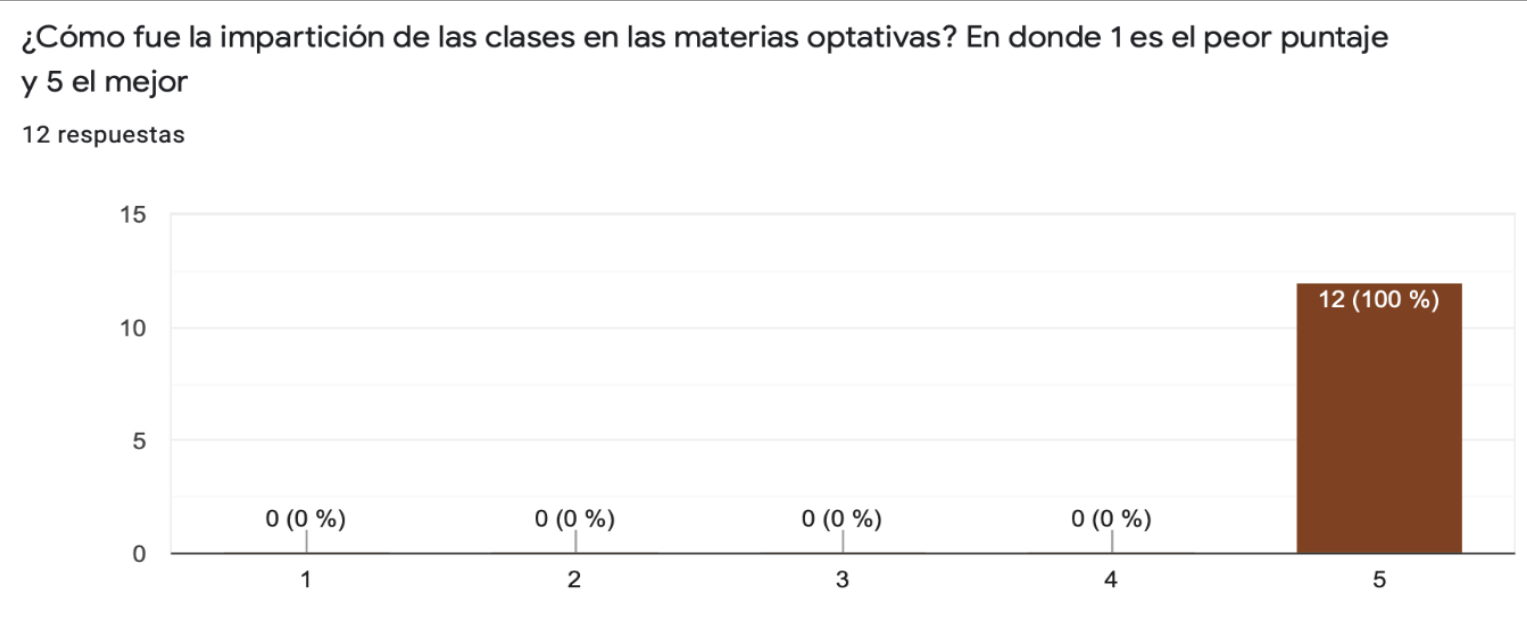

Fuente: Elaboración propia 

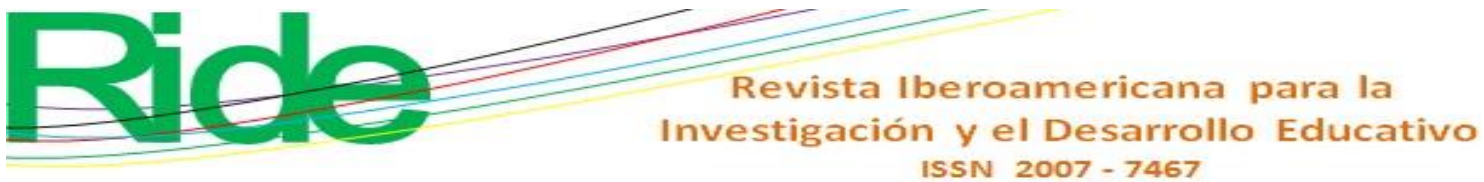

Figura 16. Pertinencia de las actividades y métodos de evaluación en el desarrollo de las tres materias optativas

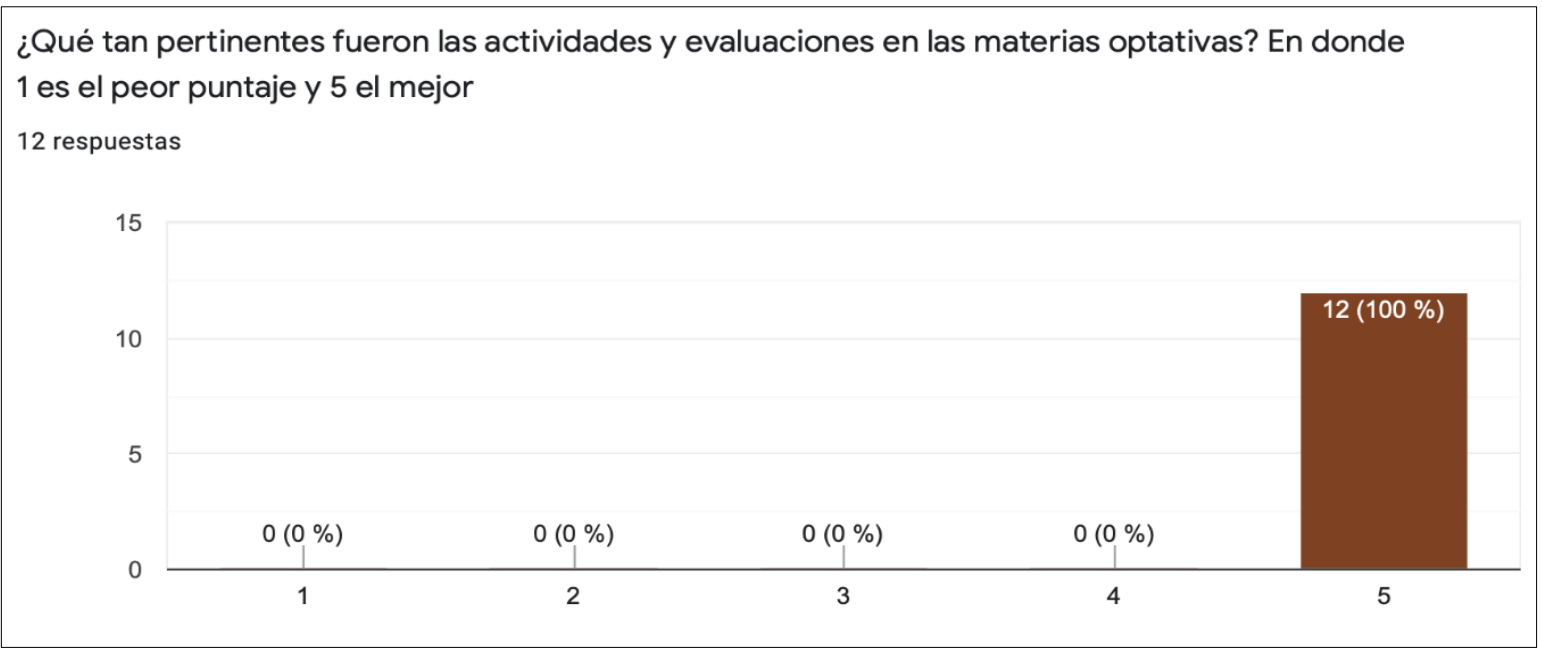

Fuente: Elaboración propia

En este punto es necesario reconocer que, como lo menciona Martínez (2012), siguiendo la idea básica que define la propuesta, se ha realizado una evaluación de acuerdo con la toma de decisiones e identificando los aspectos y dimensiones cruciales y fundamentales de las tres materias optativas que representan la estrategia para el desarrollo de las CDD en la LPP. Así, por medio de la observación y el análisis de los juicios de valor, se hizo una jerarquización y ponderación a las acciones que se tomaron, lo que dio como resultado una evaluación útil para tomar decisiones en la propuesta y deja una puerta abierta para implementar esta estrategia en otras instituciones de educación superior enfocadas en la FID que incluya una adaptación contextual.

\section{Discusión}

Implementar las asignaturas desde el enfoque de la evaluación auténtica y realizar un conjunto de actividades que permitían la reflexión del proceso de aprendizaje desde el mismo estudiante requirió el análisis concienzudo de cada actividad por parte del docente. Todo esto permitió un cambio en el proceso de enseñanza-aprendizaje, pero, a su vez, representó un trabajo arduo, un alto compromiso e inversión de tiempo. Tal vez sea por eso que algunos autores afirman: 


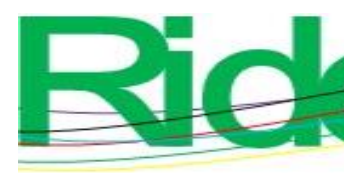

Revista Iberoamericana para la Investigación y el Desarrollo Educativo ISSN 2007 - 7467

Las innovaciones que se han pretendido introducir en la educación formal con respecto al proceso de evaluación no han sido asumidas plenamente por los profesores, y solo han generado mejoramientos puntuales que probablemente no logran configurar un proceso de enseñanza-aprendizaje renovado (Ahumada, 2005, p. 55).

Ahumada (2005) refiere que los estudiantes tienden a rechazar decididamente las formas tradicionales de trabajo que se siguen en el aula porque son contrarias a la cultura difundida por los medios en este momento. Es por eso por lo que la evaluación auténtica fue un gran apoyo para el logro de los objetivos, ya que permitió la conexión entre las actividades propuestas con las actividades que llevaban a cabo los estudiantes en otras materias.

Autores como Tobón (2017) proponen un cambio de las instituciones educativas hacia la sociedad del conocimiento, aunque para esto se requieren cambios que van desde las metodologías de gestión, planeación, implementación hasta el desarrollo de la cultura del mejoramiento continuo a través de la evaluación.

De acuerdo con lo anterior, se considera que las instituciones formadoras de docentes necesitan mantener una visión consistente para migrar a la sociedad del conocimiento, especialmente en la implementación de aplicaciones tecnológicas digitales que van a permitir el trabajo colaborativo de todos los participantes en el proceso de enseñanza-aprendizaje. No se trata de cumplir solamente con el requisito instrumental, como característica distintiva de los centros educativos, sino como parte esencial para potenciar el desarrollo social sostenible, en donde se vea reflejada una mayor calidad de vida para la sociedad y la comunidad que ha depositado la confianza en ellas.

\section{Conclusiones}

Las TIC han incursionado en todos los ámbitos de las personas y han permeado tanto que han configurado nuevos escenarios; han transformado la forma de pensar, actuar, trabajar, relacionarse, divertirse y, por supuesto, de aprender y conocer; es por eso que decimos que: las TIC son el núcleo central de organización en la sociedad actual. Por tal motivo, la escuela debe otorgar sentido al mundo que rodea al estudiante, para poder interactuar con él y enfrentar los problemas que le presente. Una razón más por la que las TIC deben estar presentes en los procesos formativos, no cabe duda de eso. 


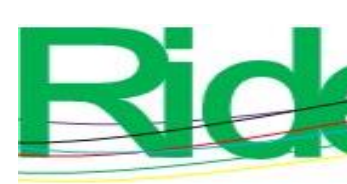

Revista Iberoamericana para la Investigación y el Desarrollo Educativo ISSN 2007 - 7467

Los nuevos escenarios educativos en donde se hace presente el carácter de ubicuidad de la tecnología digital, en donde vemos aulas y centros educativos cada vez más equipados con dispositivos digitales y en donde cada vez existen más proyectos pedagógicos y didácticos que tratan de aprovechar las bondades que la tecnología educativa ofrece, requieren de docentes preparados para hacer uso de estas herramientas.

Las instituciones de educación superior, especialmente las que se encargan de la FID, tienen un compromiso con sus estudiantes para crear espacios de aprendizaje de acuerdo con el tiempo y el espacio en los que viven, esto es, deben ir evolucionando y transformándose según el contexto. Y parte de esto es la actualización de sus planes de estudio, la capacitación docente y la adaptación de la infraestructura. Sin duda es complicado llevar a cabo estas tareas, pero se necesita hacer una planeación a corto, mediano y largo plazo.

La propuesta e implementación de la estrategia para el desarrollo de las competencias digitales en la institución de educación superior como parte de la planeación y actualización del plan de estudio hizo posible la conexión entre lo que se enseñó a los estudiantes en las tres materias optativas y lo que existe en el mundo real. El diseño de cada asignatura basado en la evaluación auténtica permitió que las temáticas abordadas y las actividades realizadas fueran desarrollándose según el propósito que se planearon. Si bien es cierto que se requiere de un trabajo arduo por parte de todos los participantes, este se llevó a cabo con un alto nivel de compromiso, especialmente por los estudiantes que identificaban elementos necesarios para llevarlos a su futura práctica docente o para desarrollar actividades propias de su proceso formativo como las prácticas profesionales y proyectos de forma transversal en la institución.

\section{Futuras líneas de investigación}

De la investigación realizada, se desprenden algunas líneas de investigación: la evaluación vista como un proceso de reflexión desde el estudiante, donde no solamente se piense como un método para la obtención de una calificación aprobatoria. Para esto también se necesitan hacer cambios desde la propuesta de planes y programas que fomenten diferentes métodos de evaluación y utilización de variedad de instrumentos y formas que muestren el desarrollo de los estudiantes, sin que de ello dependa la ponderación.

Aunado a lo anterior, es necesario realizar la búsqueda de metodologías de gestión, planeación, implementación y evaluación de asignaturas que desarrollen competencias digitales en las instituciones de educación superior encargadas de la FID en México, que 


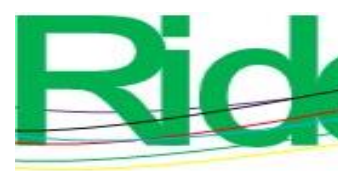

Revista Iberoamericana para la
Investigación y el Desarrollo Educativo ISSN $2007-7467$

posibiliten el desarrollo de un modelo de formación integral en relación con las TIC de los futuros docentes y poder así vislumbrar un marco común de la competencia digital docente en México.

\section{Referencias}

Ahumada, P. (2005). Hacia una evaluación auténtica del aprendizaje. Ciudad de México, México: Paidós.

Area, M. (2018). Hacia la universidad digital: ¿dónde estamos y a dónde vamos? RIED. Revista Iberoamericana de Educación a Distancia, 21(2), 25-30. Recuperado de https://doi.org/10.5944/ried.21.2.21801.

Castañeda, L. (2019). Formación inicial del profesorado en el uso educativo de la tecnología, una propuesta curricular. Quaderns Digitals: Revista de Nuevas Tecnologías y Sociedad, (89), 1-49. Recuperado de https://dialnet.unirioja.es/servlet/articulo?codigo=7087556.

Córdoba, M. E. (2013). Evaluación auténtica. Santo Domingo, República Dominicana: Instituto Tecnológico de Santo Domingo.

Correa, S., Puerta, A. y Restrepo, B. (2002). Investigación evaluativa. Bogotá, Colombia: Instituto Colombiano para el Fomento de la Educación Superior.

Díaz, F. (2006). Enseñanza situada: vínculo entre la escuela y la vida. Ciudad de México, México: McGraw-Hill.

Díaz, F. (2019). Evaluación de competencias en educación superior: experiencias en el contexto mexicano. Revista Iberoamericana de Evaluación Educativa, 12(2), 49-66. Recuperado de https://doi.org/10.15366/riee2019.12.2.003.

Escudero, T. (2016). La investigación evaluativa en el siglo XXI: un instrumento para el desarrollo educativo y social cada vez más relevante. Relieve, 22(1). Recuperado de https://doi.org/10.7203/relieve.22.1.8164.

Gil, R. L. (2018). Una mirada desafiante a la profesión docente. En La formación docente: horizontes y rutas de innovación (pp. 257-286). Buenos Aires, Argentina: Clacso. Recuperado de https://doi.org/10.2307/j.ctvnp0k1g.10.

Guzmán, L. y Ortiz, C. P. (2019). La evaluación auténtica y el rendimiento académico. (Proyecto de investigación). Universidad de la Costa, Barranquilla. 

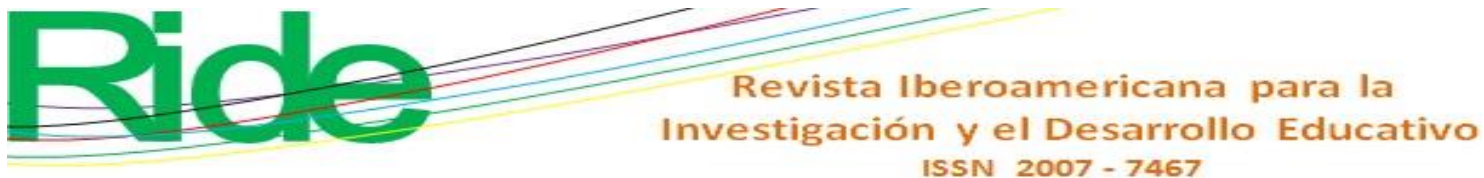

Tobón, S. (2017). Ejes esenciales de la sociedad del conocimiento y la socioformación. Mout Dora, Estados Unidos: Kresearch.

Valencia, T., Serna, A., Ochoa, S., Caicedo, A. M., Montes, J. A. y Chávez, J. D. (2016). Competencias y estándares TIC desde la dimensión pedagógica: una perspectiva desde los niveles de apropiación de las TIC en la práctica docente. Cali, Colombia: Pontificia Universidad Javeriana - Cali. Recuperado de http://www.unesco.org/new/fileadmin/MULTIMEDIA/FIELD/Santiago/pdf/Compe tencias-estandares-TIC.pdf.

Vallejo, M. y Molina, J. (2014). La evaluación auténtica de los procesos educativos. Revista Iberoamericana de Educación, (64), 11-25. 


\begin{tabular}{|l|l|}
\hline Investigación y el Desarrollo Educativo \\
ISsN 2007 - 7467
\end{tabular}

